\title{
Yeni Ă̆ Teknolojileri Bağlamında Yeni İletişim Ortamları ve Bilgi
}

\author{
Yrd.Doç.Dr. Osman Köroğlu, \\ Fatih Üniversitesi, İstanbul MYO, \\ okoroglu@fatih.edu.tr
}

Özet: $\mathrm{Bu}$ makalede yeni iletişim ortamları ve bilgi, yeni ağ teknolojileri bağlamında incelenmektedir. Yeni iletişim ortamları iletişim araştırmacıları açısından ilgi çekicidir. Çünkü sayısal, etkileşimli, hipermetinsel, sanal, ağ üstündedirler. Yeni iletişim ortamları içerik üretimi, politik katılım ve bilinçlenme gibi konularda bazı firsatlar sunar. Diğer tüm mecralarda izlerkitle sayısı azalırken internette artması bununla ilişskilendirilebilir. Yeni iletişim ortamları ve bilgi toplumu incelenirken, bloglar örnek olarak düşünülerek bilgi, demokrasi ve ekonomi de ele alınabilir.

Anahtar kelimeler: yeni iletişim ortamları, yeni ağ teknolojileri, bilgi, blog, bilgi ekonomisi

Abstract: This paper, examines new media and information in the context of new network technologies. In terms of communication researchers, new communication technologies and media are interesting. Because they are digital, interactive, hypertextual, virtual, on the network. New media provides some opportunities such as content production, political participation and awareness. This, also, can be associated with decreasing number of audience in the media other than internet. When new media and knowledge economy are examined, information, democracy and economy can be addressed with the blogs as examples.

Keywords: new media, new network technologies, knowledge, blog, knowledge economy

\section{Giriş}

Birçok akademisyen için yeni iletişim ortamları alanı ilgi çekicidir (Wardrip-Fruin ve Montfort, 2003). Medya araştırmalarının bir kısmı hedefler ve tavırlar noktasında mecraların izlerkitleleri nasıl yönlendirdiğine, bazısı da mecraların kendilerine has dillerine odaklanır (Fowler, 1991, Aitchison, ve Lewis, 2003). Toplum tarafından benimsenme hızının düşüklüğü nedeniyle, ilk eleştirel yaklaşımların ABD dışındaki ülkelerde görüldügü (Manovich, 2003) yeni iletişim ortamlarının temel özellikleri arasında sayısallık, etkileşimlilik, hipermetinsellik, sanallık, ağ üstünde olmak ve benzetime dayalı temsil sayılabilir (Lister ve di ̌̆., 2009).

Yeni ağ teknoloji ve uygulamalarındaki ana eğilim küresel entelektüel ekonomi olarak isimlendirilebilir. Günde 2 milyarın üstünde blog içeriği yayınlandığından bu doğrulanabilir (Worldometers.info, 2012). Geleneksel mecralarda izlerkitle sayısı azalmaktadır. Ancak internette artmaktadir (Stateofthemedia.org, 2011). Bireyler, Internet ile sadece enformasyon algılamaz aynı zamanda üretirler (Bruns, 2008). Bu durum sosyal medya, kullanıcının ürettiği içeriğe dayalı siteler ve bloglarda görülebilmektedir. Internet entelektüel faaliyetin ve bilgi üretiminin demokratikleştirilmesinde öncü bir ortamdır. Açık kaynaklı yazılımlar, kullanıcı kaynaklı çoklu ortam içerikleri bunun örnekleridir. Yeni iletişim ortamları, işbirliği, paylaşım ve katılımı içerir, demokratikleşme sağlayabilir (Ferdinand, 2007; Pickard, 2006). 
Yeni iletişim ortamları kişisel bilgisayarlar ve Internet incelenerek daha rahat anlaşılabilir. Bilgisayarlar arası bir yeni ăg teknolojisi olan Internet, hipermetinlerin aralarında linklenmesine dayalı olan Web teknolojisi ile birlikte yaygınlaşmıştır. Web'in gelişmesi sosyal açıdan bu ortamın önem kazanmasına ve hemen ardından da popüler ve akademik çalışmaların bu alana odaklanmasına yol açmıştır. Yeni internet kullanıcıları sosyal medyaya, video paylaşım sitelerine ve çevrimiçi ücretsiz özgür ansiklopedilere bakıldığında paylaşım ve birlikte çalışma odaklıdır. Uluslararası haber dergileri, her yıl o yılın en önemli kişi ve olaylarını seçerler. 2006'da yeni iletişim ortamlarının etkisini dikkate alan bir haftalık haber dergisi, bu ödülü "türetici" olarak da tanımlanabilen ve içerik tüketimi ile üretimini bir arada yapan bireylere verilmişti (Grossman, 2006; Bruns, 2008). Bireylerin fikirlerinin bir arada değer kazanmasını sağlayan bir araç olarak web, crowdsourcing, bloglar ve özgür yazılım gibi kavramlar ve uygulamalarla öne çıkmaktadır.

Yeni iletişim ortamları ve ağ teknolojileri açısından verimli bir inceleme ortamı sunan bloglarla ilgili akademik çalışmalar, belli başlı üç konuya odaklanırlar: geleneksel yayıncılar bu firsatı çok az oranda sunduklarından, gazetecilikle ilgili düşünceler adına bir ortam olarak bloglar; kurumsal gazeteciliğe bir meydan okuma olarak bloglar; demokratik, etkileşimli ortamlar olarak bloglar (Matheson, 2004).

\section{Yeni iletişim ortamları ve bilgi toplumu}

Yeni iletişim ortamlarını anlamak için değerlendirilebilecek birçok farklı kavram bulunabilir. Bunlar arasında yer alan düşünümsellik "bireyin kendine ilişkin deneyiminin geri dönüşü"dür (Tsekeris, 2010). Görsel ve işitsel unsurları içeren yeni iletişim ortamı teknolojileri düşünümseldir, çünkü bireylerin ve grupların kendilerinin farkında olmasını ve konumlarını değerlendirmelerini sağlar (Spielmann, 2008, s.5-17). Dünya toplumlarında, geleneksel sosyal yapılar yerine teknolojik yapılar daha etkin hale gelmektedir. Örneğin bilişim sistemi olan uzman sistemler, tıp, hukuk gibi konulardaki uzman bilgisine ulaşmada kullanılır (Greatbatch ve diğ., 2005). A ğa ister bilgisayar isterse mobil iletişim donanımları üstünden erişebilen çiftçiler, ürün ve ekim bilgilerini kullanarak, erişemeyenlere oranla daha verimli ve kârlı biçimde yetiştiricilik yapabilirler (Tenhunen, 2008).

Bununla beraber, bu durumun medyanın sosyal etkilerinin tamamını kapsayıp kapsamadığ incelenebilir. Yeni iletişim ortam ve teknolojileri sadece bu görüşlerde belirtildiği gibi bilginin geliştirilmiş biçimi olarak algılanmayabilir. Yeni ă̆ teknoloji ve uygulamaları, bireylerin birbirlerine ve ağa bağlanıp işbirliği yapabileceği daha verimli ve üretken yollar sunsa da bu sayısal bölünme tartışmalarına baklıacak olursa herkes için eşit erişim anlamına gelmemektedir (DiMaggio ve diğ., 2001). Teknolojik uygulamalar konusundaki büyük değişimleri tanımlarken kullanılan bilgi, işbirliği, bağlantılılık gibi kategorilerde de değişim gözlenmektedir.

Bilgi kuramına göre insan ve iletişim ortamları arasındaki ilişki tek yönlüdür. 21. yüzyıl toplumunda ise insan ve medya özellikle medya kültürü ve yayıncılık veya tüketici ve üreticiyi bir araya getiren türeticilik kavramı çerçevesinde yakınsamaktadır (Deuze, 2007). Medya alanında, bu durumla birlikte gazetecilik, reklamcılık, pazarlama iletişimi ve halkla ilişkiler gibi mesleklerde küresel bir çevre oluşumu görülmektedir. Bu çevrenin kültürü 
katılımcı medya kültürü olarak isimlendirilmektedir. Bu kültür içinde etkileşimli reklamcılık, halkla ilişkiler açısından iki-yönlü simetrik iletişim, yayıncılık açısından da vatandaş gazeteciliği gündemdeki kavramlar arasında sayılabilir. Ancak halen geleneksel medya ekonomisi çerçevesinde medya kurumları bireyleri reklam kurumlarına sunmak ve bu şekilde gelir elde etmek adına popüler gerçekliği biçimlendirmektedir. Bilgi, sosyal iletişim ortamları ve yeni ağ teknolojileri ile bu bağlamda ilgili tekrar düşünülerek bilgi toplumu daha iyi anlaşılabilir.

Doğrusallık tek boyutlulukla ve analog olmayla ilişkilidir (Lewis, 2005). Anlatımın zaman sıralı olmaması anlamındaki doğrusal olmama kavramı, kitaplarda ve Hollywood ve Yeşilçam sektörlerinin ürünlerinde görülebilir. Aynı durum elektronik ortamdaki linkleme ile de örneklenebilir (Heise, 1997 ve Daniel, 18.11.09). Gerek web sitesi olarak bloglarda ve gerekse mesajlaşma ortamı olarak mikro blog ortamlarında bilgi kısaltılarak sunulmaktadır. Blog içerikleri hızla üretilmekte, aktarılmakta ve basılı yayınlardan farklı güncellenmektedir. Blogların doğrusal olmayan bir özelliği de geribildirim veya yorum mekanizmasıdır. Büyük medya kurumları ise web sitelerini neredeyse sürekli güncellerler. Artık gazeteciler basılı yayına haber yetiştirmek yerine önceliği de internete vermektedirler (Ludwig ve Gilmore, 2005).

Yeni iletişim ortamları, ağ teknolojileri ve genel olarak bilim ve teknolojideki gelişmeler, birey ve toplumu hem olumlu hem de olumsuz açılardan her geçen gün daha çok hissedilen biçimde etkilemektedir. Geleneksel entelektüeller, yeni entelektüeller tarafindan yerlerinden edilmektedirler. $\mathrm{Bu}$ yeni entelektüeller, fikir üretmektense fikirlere aracılık ettiklerinden, bir fikri bir yerden alıp başka bir yere taşıdıklarından, aracılar olarak da görülebilmektedir (Cummings, 2003). Bilgi çalışanları, her ne kadar geleneksel işçilere kıyasla daha çok kas gücü yerine beyin gücü kullansalar da, geleneksel anlamdaki entelektüeller değillerdir. Aracı entelektüeller, yoktan var etmez ama kolaylaştırır, düzeltir, hızlandırır, sadece fikirleri hareket ettirir (Cummings, 2003). Bu hareket ettirme yeni iletişim ortamlarındaki ve ağ teknolojileri ile sunulan hizmetlerdeki içerik üretim ve paylaşımındaki linkleme olgusunda veya kısaca paylaşım kültüründe gözlemlenebilir.

\section{Bloglar açısından bilgi, demokrasi ve ekonomi}

Yeni ağ teknoloji ve uygulamaları araştırılırken, blogların politik etkisi gözlemlenmiştir (Woodly, 2008). Woodly, yeni iletişim ortamlarının kitlesel iletişim ortamı olarak geleneksel mecraların yerini alacağı yönündeki görüşlerin en azından belli oranda geçersiz olduğunu belirtir. Geleneksel mecralar halen en popüler web sitelerinden daha çok insana ulaşmaktadır. Ancak özellikle bloglar, görüşlerin harekete geçirilmesi ve gazeteciler ve politikacilar gibi önde gelen politik kişilerin gündemlerinin belirlenmesinde yardımcı olabilirler. İlgili bireyler açısından blogların sağladığı avantaj hem bir bilgi kaynağı olması hem de politik süreçlerde katılımcılık konusunda tartışmaya dayalı yapılarıyla yardımcı olmalarıdır.

Bloglar bağlantıları ve yapısıyla sivil toplum için alternatiftir (Vatrapu ve diğ., 2008). Bunu kamusal alan olarak konumlandırıldıkları ve çevrimiçi tartışma ortamı olarak kullanıldıklarında gerçekleştirirler. Gerçekte sivil toplum için bloglar ve Internet faydalıdır çünkü sosyal konumları nasıl olursa olsun herkese bir anda ulaşma firsatı sunar. Yeni iletişim 
ortamları ağa dayalıdır ve farklı içerikler farklı biçimlerde iletilebilir. Oysa geleneksel mecralarda tek içerik biçimi, merkezdeki yayıncıdan tüm izlerkitleye iletilir. Ağda ise yayıncı ve izlerkitle sürekli rol değiștirir (Castells, 1996).

Haber blogları, katılımcı gazetecilik hareketlerini de başlatmıştır (We Media, 2003). Yayıncılık, haberlerdeki eşik bekçisi rolünü, teknolojilere, rakiplere ve son olarak da izlerkitlelere bırakıyor. Yeni iletişim ortamları ve mobil iletişim, izlerkitleye içerik üretim ve yayınında katılımeı olma firsatı sunuyor. Buna rağmen, yeni iletişim ortamları genelde demokratik görülse bile (Kolsaker ve Lee-Kelley, 2006), insan ve teknoloji ilişkisini düzenleyerek bilgiyi başkalaştırdıkları da savunulabilir. Bu konulardaki çalışmalarda vatandaşların teknolojiyi kabulü, çevrimiçi kamu hizmetlerini kullanma konusundaki yetenek ve istekleri ile sayısal uçurum ve bölünme konuları sıklıkla ele alınır.

Yeni iletişim ortamlarının küresel bilginin geçiş kanalı olduğunu savunanlar bilgi ve küresel bilgi toplumu politikalarında demokrasi gibi unsurları karıştırabilir. Bilginin varsayılan bir etkisi de özgürlüktür (Audi, 1993). Ancak bu bilgiye erişebilmeyi, anlayabilmeyi ve kullanabilmeyi de gerektirir. $\mathrm{Bu}$ da ancak medya, teknoloji, enformasyon ve bilgi okuryazarlığı ile söz konusu olabilir. Yeni iletişim ortamları ve teknolojileri ile insanın ve medyanın yakınsaması sonucu, artık enformasyon denilen ve veriden hemen sonra gelen unsura erişebilmek, bilgelik kavramı öncesi son adım olan bilgiye erişip, hazmedip ardından kullanabilmek kadar değerli değildir. Bundan sonraki aşama da kullanılan bu bilgi ile ekonomik değer üretebilmek ve bu sayede bilgi ekonomisi oluşturabilmektir.

Bilgi ekonomisi kavramının kökenleri incelendiğinde iki isimle karşılaş1lır: Peter Drucker (1969) ve Fritz Machlup (1962). Kavram iki türlü anlaşılabilir: Ekonomik kısıtlar içerisinde bilginin üretilmesi ve yönetilmesi veya bilgiye dayalı ekonomik faaliyetler bütünü. İkinci anlamdaki kullanımıyla bilgi teknolojilerinin kullanımı sayesinde iş fırsatları ve ekonomik faydalar elde edilmesi de kastedilir. İki anlayış arasındaki temel fark, bilgi ekonomisinde bilgi ürün, bilgiye dayalı ekonomide ise araçtır. Küreselleşme ve enformasyon teknolojileri bilgi ekonomisinin arkasındaki itici güçlerdir. Enformasyon teknolojileri ise yeni iletişim ortamları ve yeni ă̆ teknolojileri ile doğrudan ilişkilidir. Günümüz küresel ekonomisi, enformasyon toplumunun bir uzantısı olarak bilgi ekonomisine doğru dönüşmektedir denilebilir.

Bilgi açısından bu sayılanları değerlendirdiğimizde şu sonuçlara ulaşılabilir: Ekonomi sınırlı kaynakların paylaşımı konusundaki sorunlara odaklıdır. Ancak bilgi ekonomisinde ürün olan bilgi, paylaşılarak ve uygulanarak çoğalır ve gelişir. Yeni iletişim ortamları ile gelişmekte olan yayıncılıkta da durum bu şekildedir. Üstelik yüksek talep ve düşük seviyedeki engeller neredeyse bilgi akışı o yöndedir. İçeriklerini ücretli olarak sunan yayıncıların durumuyla her gün milyonlarca kişiye ulaşan blogların durumu kıyaslanarak bunun doğruluğu görülebilir. Aynı zamanda, bilgi içerikli ürünler, içeriğinde bilgi az olan daha düşük seviyeli ürünlere kıyasla çok daha pahalıdırlar. Bir gelir sağlama modeli olarak, blog yazarlarının, belli bir içerik birikiminden sonra, yazı ve düşüncelerini kitaplaştırarak elektronik veya basılı ortamda sunmaları buna örnek olarak verilebilir. İletişim bilgi akışı konusunda gittikçe artan oranda önem kazanmaktadır. Sosyal yapılar, kültürel bağlam ve diğer etkenler sosyal ilişkileri ve dolayısıyla bilgi ekonomisini etkiler. 


\section{Sonuç}

Mecralar tek başlarına değerlendirildiğinde farklı biçimlerde anlaşılabilirler. Ancak bir arada, birey ve topluma etkileri açısından incelendiklerinde o ana dek farkedilmeyen şeyler ortaya çıkarılabilir. Bireyler sayısal ağlarda bilgiye erişmek dışında artık bilgi de üretmektedirler. $\mathrm{Bu}$ açıdan bireylerin insanlık tarihi boyunca fikirlerini ve düşüncelerini başkalarıyla paylaşma konusunda hiç bu kadar özgür olmadıkları söylenebilir. $\mathrm{Bu}$ da bir anlamda demokratikleşmeye hizmet eder.

Yeni iletişim ortamları ile olan çift yönlü ilişkileri nedeniyle türetici olarak da isimlendirilebilen bireyler, kişisel web sitelerinin çok daha kolay üretilebilen ve günlük olarak düşünülebilecek biçimi olan bloglar sayesinde, adeta yayıncılıkla ilgili düşünebilirler, kurumsal medyaya alternatif bir ortam oluşturabilirler ve kendileri gibi olan kişilerle etkileşime girebilirler.

Bireyler ve gruplar yeni iletişim ortamlarında bir araya gelerek kendilerinin farkına varır ve herhangi bir konuda bulundukları durumu ve konumlarını gözden geçirirler. Bazı durumlarda bunun anlamı geleneksel yapılar yerine teknolojik yapıların daha yaygın ve geçerli hale gelmesidir.

Ancak tüm bunlar sayısal uçurumun "sahip olanlar" tarafinda kalanlar için geçerlidir. $\mathrm{Bu}$ kişiler işbirliği ve bağlantılılıktan yararlanarak diğerlerinden daha farklı bir hayat sürebilirler. Ürettikleri içerikler ile politik gündemleri etkileme konusunda çaba gösterebilir, sivil toplum hareketlerini üretip, biçimlendirip, geliştirebilirler. Bunların gerçekleşmesi için gereken ise, temel seviyede medya, teknoloji, enformasyon ve bilgi okuryazarlığıdır.

\section{Kaynaklar}

Aitchison, J. ve Lewis, D.M., (2003), New Media Language. London:Routledge

Audi, R. (1993), "Modalities of Knowledge and Freedom" İçinde: Robert Audi, (Ed.) Action, Intention, And Reason. Ithaca:Cornell University Press.

Bruns, Axel (2008) "The Future Is User-Led: The Path towards Widespread Produsage". Fibreculture Journal, eprints.qut.edu.au/12902, Fibreculture Publications, Perth, WA.

Castells, M. (1996), The Rise of the Network Society. Cambridge, MA; Oxford: Blackwell Publishers.

Cummings, D. (2003) "Ideas, Intellectuals and the Public", Critical Review of International Social and Political Philosophy, 6:4, s. 1-7

Daniel, S. (18.11.09), "Public Secrets." Vectors Journal of Culture and Technology in a Dynamic Vernacular, vectors.usc.edu/issues/4/publicsecrets/, Erişim: 13.03.12

Deuze, M. (2007), "Convergence culture in the creative industries", International Journal of Cultural Studies, 10:2, s.243-263 
DiMaggio, P., Hargittai, E., Neuman, W.R. ve Robinson, J.P. (2001), "Social Implications of the Internet", Annual Review of Sociology, Vol. 27, s.307-336

Drucker, P. (1969), The Age of Discontinuity. New York: Harper and Row

Ferdinand, P. (2007), "The Internet, democracy and democratization", Democratization, (7:1), 2007, s.1-17

Fowler, R. (1991), Language in the News: Discourse and Ideology in the Press, London:Routledge.

Greatbatch, D., Hanlon, G., Goode, J., O'Cathain, A., Strangleman, T. ve Luff, D. (2005), "Telephone triage, expert systems and clinical expertise", Sociology of Health \& Illness, 27:6, s. $802-830$.

Grossman, L. (25.12.06), "You - Yes, You - Are TIME's Person of the Year", time.com/time/magazine/article/0,9171,1570810,00.html, Erişim: 13.03.12

Heise, U.K. (1997), Chronoschisms: Time, Narrative, and Postmodernism. Cambridge University Press. s. 7

Kolsaker, A., Lee-Kelley, L. (2006), “'Mind the gap': e-government and e-democracy”. İçinde: Proceedings of the 5th international conference on Electronic Government (EGOV'06), Maria A. Wimmer, Hans J. Scholl, Ake Grönlund, and Kim Viborg Andersen (Ed.). Springer-Verlag, Berlin, Heidelberg, s.96-106

Lewis, A. (2005. Wordweb dictionary, Linearity item, based on Princeton Wordnet database.

Lister, M, Dovey, J. Giddings, S. Grant, I. ve Kelly, K. (2009), New Media: a critical introduction. London:Routledge

Ludwig, M.D., Gilmore, G. (2005), Modern News Editing, s.14, Blackwell Publishing

Machlup, F. (1962), The Production and Distribution of Knowledge in the United States. Princeton: Princeton University Press

Manovich, L. (2003), "New Media from Borges to HTML" The New Media Reader içinde. s.13, (ed.) N. Wardrip-Fruin ve Nick Montfort. Cambridge, MA:MIT Press

Matheson, D. (2004), "Weblogs and the Epistemology of the News: Some Trends in Online Journalism”, New Media \& Society, Ağustos 2004 6:4, s.443-468

Pickard, V.W. (2006), "Assessing the radical democracy of indymedia: discursive, technical, and institutional constructions". Critical Studies in Media Communication, 25:1, s.19-38.

Spielmann, Y. (2008), Video: the reflexive medium, MIT Press

Stateofthemedia.org. (2011), "Key Findings", stateofthemedia.org/2011/overview-2/keyfindings, Erişim: 13.03.12 
Tenhunen, S. (2008), "Mobile technology in the village: ICTs, culture, and social logistics in India". Journal of the Royal Anthropological Institute, 14:3, s.515-534

Tsekeris, C. (2010), "Reflections on Reflexivity: Sociological Issues and Perspectives", Contemporary Issues, 3(1), s.28-37.

Vatrapu, R., Robertson, S. P. ve Dissanayake, W. (2008), “Are political weblogs public spheres or partisan spheres?”, International Reports on Socio-Informatics, 5(1): s.7-26

Wardrip-Fruin, N. ve Montfort, N. (ed.). (2003), The New Media Reader. Cambridge, MA:MIT Press

We Media (2003), "Chapter 1: Introduction to participatory journalism" hypergene.net/wemedia/weblog.php?id=P36, Erişim: 13.03 .12

Woodly, D. (2008), "New competencies in democratic communication? Blogs, agenda setting and political participation", Public Choice, 134:1, s. 109-123

Worldometers.info, (2012), "Blog posts written today", www.worldometers.info/blogs, Erişim: 13.03 .12 